\title{
Urdimento
}

Revista de Estudos em Artes Cênicas E-ISSN: 2358.6958

\section{A fenomenologia da máscara neutra}

Evandro Luís Teixeira

\section{Para citar este artigo:}

TEIXEIRA, Evandro Luís. A fenomenologia da máscara neutra. Urdimento, Florianópolis, v. 3, n. 39, nov./dez. 2020.

DOI: http:/dx.doi.org/10.5965/14145731033920200207

Este artigo passou pelo Plagiarism Detection Software | iThenticate 


\title{
A fenomenologia da máscara neutra
}

\section{Evandro Luís Teixeira ${ }^{1}$}

\begin{abstract}
Resumo
Neste artigo proponho uma aproximação conceitual entre o recurso expressivo conhecido como Máscara Neutra e a abordagem filosófica chamada de Fenomenologia. Procuro descrever em linhas gerais os princípios da atuação com esse tipo de máscara, que originalmente era chamada de Nobre, e faço uma comparação de seus princípios com alguns aspectos do método fenomenológico. Por fim, problematizo a relação entre o ator e a máscara, tentando provocar o leitor a questionar certos paradigmas representacionais.
\end{abstract}

Palavras-chave: Máscara Neutra. Fenomenologia. Teatro de Máscaras.

\section{The Neutral Mask's Phenomenology}

\begin{abstract}
In this article, I propose a conceptual approach between the expressive feature known as the Neutral Mask and the philosophical approach called Phenomenology. I try to describe in general terms the principles of acting with this type of mask, which was originally called Noble, and I compare its principles with some aspects of the phenomenological method. Finally, I question the relationship between actor and mask, trying to provoke the reader to question certain representational paradigms.
\end{abstract}

Keywords: Neutral Mask. Phenomenology. Masks Theater.

\section{Fenomenologia de la máscara neutral}

\section{Resumen}

En este artículo, propongo un enfoque conceptual entre lo recurso expresivo conocido como la Máscara Neutral y un enfoque filosófico llamado Fenomenología. Proceda a describir en general los principios de acción con este tipo de máscara, que se llamó Nobre, y haga una comparación de sus principios con algunos aspectos del método fenomenológico. Finalmente, problematice una relación entre actor y máscara, intente provocar o leer un cuestionario sobre ciertos paradigmas representativos.

Palabras clave: Máscara neutral. Fenomenología Teatro de máscaras. 
O uso da máscara nos ajudava interiormente a nos libertar de nós mesmos, criando em nós uma espécie de vazio de onde jorrava aquilo a ser expresso (quando estávamos inspirados) de modo totalmente diferente de quando estávamos com o rosto descoberto.

(Jean Dasté apud Freixe, 2010, p. 115)

Existem exercícios de teatro com o uso de máscaras que podem ser considerados bastante desafiadores até mesmo ao mais experiente ator. Aparentemente, escondido por trás de uma falsa simplicidade, o exercício pode parecer fácil quando olhado de fora, visto pelo viés do espectador desatento ou do ator desinteressado em trabalhar o seu repertório gestual, mas quando observado com atenção ou colocado seriamente em prática no treinamento do ator, o exercício contém em si a capacidade extraordinária de fazer o ator repensar as suas estratégias de atuação. Trata-se de "despertar" uma máscara neutra.

Pode parecer exagero aceitar a ideia de que uma máscara ganha vida nas mãos de um ator. Não estamos falando aqui de uma experiência sobrenatural, tampouco de uma pesquisa com robótica ou inteligência artificial, mas sim de procedimentos de atuação capazes de despertar no espectador a ilusão de uma nova realidade. Pode-se dizer que no campo de pesquisa do teatro de animação, há de se supor, que as principais questões estão lançadas sobre o ato de criar a impressão de vida em um objeto inanimado - ainda que seja no sentido figurado. No caso do teatro de máscaras, o objeto inanimado ganha contornos, não apenas de uma extensão do corpo do ator, mas de uma segunda natureza que coabita o mesmo ser.

Se você não está familiarizado com certas vertentes da pedagogia teatral, talvez esteja se perguntando: o que seria uma máscara neutra? Em oposição às máscaras expressivas, a máscara neutra pode ser compreendida como um tipo de máscara que não deve apresentar características de identidade distinguíveis ou acentuar determinados sentimentos como, por exemplo, alegria ou tristeza. A máscara neutra tampouco deve apresentar deformidades, mas sim suavizar as expressões e buscar um olhar sereno e contemplativo, não exibicionista, 
apagando, em seu desenho e sua confecção, os traços pessoais do ator em busca de uma ingenuidade sutil.

A origem da máscara neutra pode ser detectada no começo do século XX, na França. Uma série de experiências inovadoras na cena teatral europeia, como as encabeçadas por Edward Gordon Craig (1872-1966), Vsevolod Emilevich Meyerhold (1874-1940) e Jacques Copeau (1879-1949), entre outros, constituíam uma tentativa profícua de produzir um novo teatro, ou no mínimo, um teatro renovado. Podemos compreender melhor este momento histórico a partir da leitura do livro Les Utopies du masque sur les scènes Européennes du XXe siècle [As utopias da máscara na cena europeia do século XX] de Guy Freixe (2010). O que podemos perceber a partir da leitura de Freixe é que, as máscaras, de uma forma geral, desempenharam um papel fundamental na concepção desse novo teatro europeu. É curioso pensar sobre o papel que a máscara desempenhou nesse contexto. Especialmente se levarmos em conta que a máscara, apesar de estar presente na arte desde os períodos mais remotos da humanidade, desde sempre esteve associada ao teatro. Desde os rituais mais primitivos até os dias de hoje, a máscara está presente nas mais diversas culturas, da cultura pop até as mais exóticas. Podemos até pensar que a máscara seria o objeto essencial para a transfiguração da persona, tão antiga quanto a própria ideia de teatro - especialmente se pensarmos no teatro grego, originário do termo theatron. Como poderia o elemento fundamental do teatro ser a peça principal para essa inovação? É preciso levar em conta que esse artefato milenar havia perdido a sua força e caíra em desuso desde que a ideia de naturalismo se apossara das tendências artísticas.

Assim, na virada do século, o corpo foi exaltado e ao mesmo tempo instrumentalizado, mecanizado, posto ao serviço de uma ideia. Pois foi primeiramente o encenador, e não o ator, quem se viu envolvido no movimento de renovação dramática. Pôr máscara no ator aparecerá, então, como uma solução prática para o problema delicado da formatação do corpo do ator em cena.

Paradoxalmente, porém, a máscara - que só deveria servir para que esquecêssemos o corpo julgado indigno da arte - dará ao ator a consciência das possibilidades expressivas da linguagem corporal, o despertará para a qualidade do gesto e the ensinará as leis dinâmicas do movimento no espaço. A máscara, que deveria apenas esconder o ator, finalmente revelará nele a parte oculta do criador. (Freixe, 2010, p. 22). 
Curiosamente, esse artifício, que no século XVIII havia sido excluído dos palcos por Carlo Goldoni (1707-1793) em nome de uma humanização das personagens, assim como as perucas e a maquiagem, que em nome de uma "bela natureza", haviam sido rechaçadas da dança por Jean-Georges Noverre (17271810) recuperou seu lugar na cena.

Daí para a frente, o artista fica desconfiado perante a ideia de "natureza" e de "natural". Notemos que um século antes a máscara havia sido expulsa de cena para se aproximar desses valores. Assim, a personagem de Arlequim - que se interpretava ainda com máscara em 1720 em Arlequin poli par l'amour [Arlequim polido pelo amor], de Marivaux — se humanizará, deixando nos bastidores a sua máscara tradicional. Em sua briga com Gozzi, Goldoni também fará da exclusão da máscara a condição necessária para poder retratar com verdade os caracteres; e Noverre imporá a sua reforma da dança retirando as máscaras e as perucas em nome da "bela Natureza". (Freixe, 2010, p. 17).

A máscara ressurgiu neste começo do século XX aparentemente como uma forma de oposição a um realismo já desgastado e enfraquecido. Ao mesmo tempo, esse retorno evidenciou uma condição crítica, apontada por Guy Freixe: a noção de personagem foi colocada em crise, assim como a compreensão de sujeito moderno. Essa sensação de expropriação do Eu, sintetizada tão bem pela afirmação inquietante de Arthur Rimbaud (1854-1891): "Eu é um outro"2 (Rimbaud, 1984, p. 200) é uma constatação que denota a ruptura dos novos tempos com a filosofia humanista do Iluminismo. A razão deu lugar à dúvida e a máscara era o elemento capaz de revelar a angústia dessa expropriação, retomando a confiança na renovação da linguagem teatral. (Freixe, 2010).

Nessa passagem da Belle Époque para os Années Folles ${ }^{3}$, a Europa foi assolada pela I Guerra Mundial. O velho continente que já vinha sendo agitado por revoluções, tornou-se palco de complexas disputas ideológicas e posicionamentos políticos extremos. Foi ao mesmo tempo um momento de enorme proliferação da arte moderna. Percebe-se, nessa época, uma verdadeira necessidade de ruptura

${ }^{2}$ Carta de Rimbaud a Georges Izambard, 13 de maio de 1871.

${ }^{3}$ Em referência ao período entre-guerras conforme sugerido em: Jean-Jacques Leveque, 1992. 
com a arte tradicional, haja vista o surgimento de inúmeros movimentos artísticos, caracterizados muito bem pelos manifestos que foram publicados, como o do futurismo ${ }^{4}$ e o do dadaísmo ${ }^{5}$. Toda essa movimentação acabou provocando um acirramento dos debates estéticos que impulsionaram a produção artística para um novo limiar. Envolvida nesse contexto, a máscara seria utilizada de diversas formas e com os mais peculiares objetivos. É possível se observar, sobretudo em espetáculos emblemáticos dessa época, uma variedade de técnicas de atuação e propostas dramatúrgicas concernentes com esta afirmação. A ideia de mascarar o corpo, consagrada pelo Pierrô do ator/encenador russo Vsevolod Meyerhold em A Barraca de Feira (1907), assim como a ideia de um corpo todo mascarado, conforme realizado pelo balé Parade (1917), sob a concepção artística do espanhol Pablo Picasso (1881-1973), exemplificam um pouco esse rico horizonte de proposições estéticas exploradas durante este período. A máscara, para esses novos encenadores, havia retornado com toda força e essa potência artística tornou evidente sua importância nesse processo de renovação teatral.

Sobre esta volta da máscara no teatro do século $X X$, em seu livro O Ator $e$ Seus Duplos, Ana Maria Amaral também se pronuncia, dizendo que:

No início do século XX, houve à volta à máscara. As razões foram várias. Principalmente influiu a descoberta da arte primitiva africana e sua assimilação por artistas europeus, os dadaístas, os cubistas e futuristas. O rosto passou a ter, na pintura, uma relação diferente com o corpo. Também influíram os contatos com o Teatro Nô do Japão, com Bali e Java. Outra influência é atribuída, por Denis Bablet, ao ressurgimento do esporte no final do século XIX. Segundo ele, o retorno dos jogos olímpicos em 1896, provocou uma conscientização do corpo. Essa preocupação se refletiu na arte, como se pode ver nas esculturas de Rodin e na dança de Isadora Duncan. Houve como que uma descentralização do corpo humano, o rosto perdeu sua hegemonia e passou a ser uma simples parte do todo. (Amaral, 2002, p. 51).

O profeta desse retorno da máscara à cena moderna foi o inglês Edward

${ }^{4}$ O Manifesto Futurista foi escrito pelo poeta italiano Fillippo Tommaso Marinetti e publicado no jornal francês Le Fígaro em 20 de fevereiro de 1909. Nota do autor.

${ }^{5}$ O Manifesto Dadaísta foi escrito por Hugo Ball em 14 de julho de 1916 e lido no mesmo dia no Waag Hall em Zurique. 
Gordon Craig (1872-1966) que a partir da fundação da sua revista The Mask em 1908 redefiniu os parâmetros do pensamento do teatro europeu. Bastante influenciado pela filosofia de Friedrich Nietzsche (1844-1900), Craig estava decidido a implodir as bases do teatro tradicional, a começar pelo ator. O programa de sua revista alimentava ideias de um "novo teatro", com uma concepção estética divergente ao realismo, centrado na máscara, em marionete e nas artes plásticas. Seus editoriais, ao mesmo tempo em que propunham um teatro do futuro, revolviam o passado em busca de formas de teatro ancestrais. Foi assim, segundo Freixe, que em 1911 foram publicados os primeiros estudos sérios sobre a Commedia dell'Arte, seguidos, a partir de 1912, por estudos sobre o teatro japonês, chinês e indiano. Ao longo desse começo do século XX, a influência de Craig havia se espalhado pelas principais capitais da Europa. De março de 1908 a outubro de 1929, craig editou praticamente sozinho (com a ajuda de uns poucos colaboradores e de vários pseudônimos), essa revista que teve influência determinante para a renovação do teatro europeu. (Freixe, 2010).

\section{A Máscara Nobre}

Inspirados pela profética revista de Craig, Jacques Copeau (1879-1949) e Charles Dullin (1885-1949), encontraram na máscara o ponto de convergência em suas práticas de treinamento do "novo ator" (Freixe, 2010, p. 120). Dentre essas práticas, sabe-se com a leitura de Freixe que, inicialmente os atores faziam exercícios com os rostos cobertos por algum tipo de malha fina e que, a partir de dezembro de 1921, começaram a confeccionar as suas próprias máscaras que ficariam conhecidas como "Nobres" (Freixe, 2010, p. 137). As máscaras chamadas de nobres, talvez pela suavidade de seu traços, podem até ter sido inspiradas na tradição do teatro Nô japonês, não existem evidências sobre isso, apesar do aparente fascínio de Copeau pelo estilo oriental. Contudo, é preciso levar em conta que essas máscaras desempenhavam uma função diferente do convencional. Ao invés de serem utilizadas em cena, para o público, as máscaras Nobres eram máscaras de treinamento, não faziam parte da apresentação do espetáculo. Buscavam ajudar o ator a alcançar um controle mais técnico do seu gestual, assim 
como a estudar a curva dramática de uma obra por meio da pantomima. As utilidades de uma máscara para treinar eram muitas. Em especial, ajudavam no processo de aprendizagem dos novos atores, considerados como a peça fundamental para o surgimento do novo teatro.

Um exercício de despertar a máscara foi descrito por Charles Dullin em Souvenirs et notes de travail d'un acteur (1946). Sabe-se que esse exercício constituía parte do treinamento do ator na escola de teatro Atelier, fundada entre 1921 e 1922 em Paris pelo próprio Dullin, assim como já se fazia na École du Vieux Colombier, dirigida por Jacques Copeau. Antes de organizar sua escola de teatro, Dullin - que havia se tornado um dos principais atores da companhia do Théâtre du Vieux Colombier - trabalhava em estreita colaboração com Jacques Copeau, desde 1912 quando contracenaram em Les Frères Karamazov, dirigidos por Jacques Rouché (1862-1957). Esse profícuo relacionamento possibilitou que ambos compartilhassem muitas das práticas hoje consolidadas na pedagogia teatral.

Esse trabalho com a máscara nobre acabou trazendo grandes contribuições não apenas para o campo estético, mas sobretudo para a pedagogia do teatro. A máscara nobre não era apenas um acessório de cena, ou um mero adereço do ator, era parte essencial de um completo processo de formação e de todo um estudo da atuação com o intuito de refinar o gestual em substituição das caretas e expressões forçadas, que serviam de "muleta" para os atores da época, uma prática amplamente criticada por Copeau em seus escritos sobre o teatro. Freixe explica a ideia por trás da denominação de "nobre":

A máscara "nobre" é uma máscara de calma, em que o rosto deixa os limites da subjetividade e acolhe a universalidade do homem. Se Copeau escolheu esse qualificativo - 'nobre' - , foi porque essa máscara era, para ele, o meio de apagar as caretas e os tiques que habitualmente deformam a atuação do ator. Ela possibilitava uma abertura para algo maior que si mesmo. (Freixe, 2010, p. 132).

Célebres atores, como Louis Jouvet (1887-1951), Antonin Artaud (1896-1948), Étienne Decroux (1898-1991), Jean Dasté (1904-1994) e Jean-Louis Barrault (19101994), provavelmente em algum momento de sua formação teatral, foram 
desafiados por alguma variação deste exercício de despertar uma máscara neutra, seja em aulas no Atelier (onde acredito se utilizava uma meia máscara que deixava a boca livre, para ajudar na respiração do ator) e no Vieux-Colombier (onde se usava a máscara nobre masculina e feminina feita com a técnica de papietagem).

Figura 1 - Máscaras usadas em espetáculos de Jean Dasté da Comédie de Saint-Étienne. Produzida ${ }^{6}$ na casa de Cathérine Dasté (neta de Jacques Copeau) em janeiro de 2017, na França

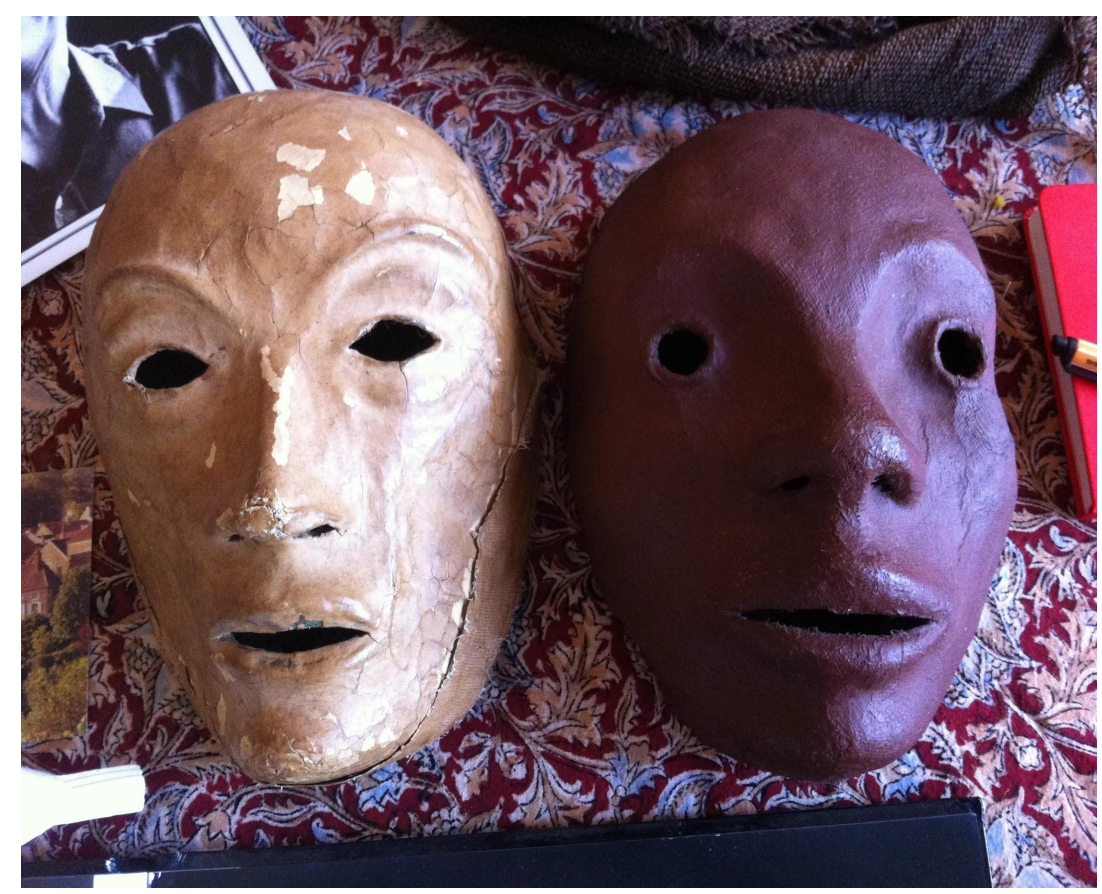

A máscara chamada de nobre por Copeau e Dullin, foi retomada por Jean Dasté (1904-1994), inclusive sob a forma de espetáculo com a Comédie de SaintÉtienne (Ver figura 1), e mais tarde apropriada sob a nomenclatura de máscara neutra por Jacques Lecoq.

Podemos ressaltar a influência dessa máscara a partir da sua relação com o surgimento da mímica moderna. É impossível não reconhecermos a influência que o trabalho com a máscara nobre representou no percurso profissional de Etienne Decroux (1898-1991), principal expoente da mímica moderna, se levarmos em

${ }^{6}$ Durante a pesquisa para a dissertação de mestrado, intitulada Vestígios de uma encenação quase esquecida. A Ilusão, de Jacques Copeau, tive a oportunidade de entrevistar Cathérine Dasté, a neta de Jacques Copeau. $\mathrm{Na}$ ocasião ela me surpreendeu com inúmeras máscaras de seu pai, Jean Dasté, dentre as quais estavam algumas máscaras "Nobres". 
conta que ele foi que foi um dos alunos da École du Vieux-Colombier. Podemos acrescentar também que Decroux foi quem conseguiu visualizar um novo potencial para os exercícios com a máscara, sem a máscara. Também é admissível verificar que esta tendência pedagógica influenciou toda uma vertente daquilo que ficou conhecido como Teatro Físico, a partir de Jacques Lecoq. Philippe Gaulier (1943) e Monika Pagneux (1951). Podemos constatar que essas experiências citadas contribuíram de maneira significativa para o desenvolvimento de certas tendências da pedagogia e estética teatral da segunda metade do século XX (Romano, 2013, p. 49-65).

O treinamento com a máscara neutra continua a ser realizado até os dias de hoje nos cursos iniciais da École Internationale de Théâtre Jacques Lecoq (com máscaras feitas de couro a partir da influência do escultor italiano Amleto Sartori), conforme podemos ver no site da escola?. A máscara neutra está contemplada também no programa de cursos da escola de Philippe Gaulier e está presente em tantas outras propostas de formação teatral espalhadas pelo mundo, como por exemplo na graduação em Teatro da Universidade do Estado de Santa Catarina (UDESC), no Brasil, onde tomei conhecimento dela.

\section{A subjetividade do ator e a objetividade de sua arte}

A permanência da máscara em programas de treinamento do ator, supõe-se que se deva ao empoderamento que esta técnica oportuniza ao ator em sua aprendizagem teatral. Isso ocorre na medida em que o ator mascarado ganharia confiança e começaria a se libertar da sua identidade cotidiana, sobretudo, se pensarmos do ponto de vista da aprendizagem do jovem aspirante. Tendo experimentado essa sensação, o ator passaria a responder de maneira diferenciada às exigências da cena, deliberando com menos juízo de valor sobre suas ações, entregando-se mais facilmente ao domínio da personagem. Supõe-se que, sentindo-se seguro pelo rosto oculto, o ator atuaria protegido sob a efígie da máscara.

${ }^{7}$ Disponível em « http://www.ecole-jacqueslecoq.com ». 
Nas palavras de Lecoq (1997, p. 115):

A máscara neutra, que acreditamos feita para se esconder, nos coloca a nu. Nosso rosto-máscara da vida cai, o papel que ele representava não tem mais sentido. Nós sentimos cada movimento de nosso corpo com mais acuidade. Os gestos se tornam maiores e ficam lentos.

Acompanhando essa mesma linha de raciocínio, segundo Guy Freixe, para Dullin "a máscara age como um instrumento libertador" e para realizar este exercício o ator deveria "esquecer o máximo possível seu corpo e sua gravidade e procurar uma descontração completa, um 'aniquilamento total'”. Espera-se que o ator consiga, de alguma forma se desconectar de si, tornar-se impessoal, procurando um tipo de vazio, como se o silêncio o preenchesse. Lecoq (1997) usava a metáfora da folha em branco sobre a qual se inscreverá a escritura do drama. Como se o corpo humano fosse capaz de atingir um estado de neutralidade, um ponto zero, um esvaziamento das individualidades cotidianas. "Chegado a esse vazio e sensível àquele ser profundo e impessoal que está nele, [...] [o ator mascarado] desperta, abre os olhos, e descobre o mundo." (Freixe, 2010, p. 152).

Essa (re)descoberta, no âmbito dessa pesquisa sobre a proposta do exercício, constitui a tomada de uma nova consciência corporal, um outro modus operandi, compreendido pela busca de uma expressão livre e fluida. Segundo Dullin, essa expressão livre e fluida poderia acontecer "a partir desse estado de escuta e de receptividade de todos os circuitos sensoriais e imaginativos" (Dullin apud Freixe, 2010, p. 152). O estado de escuta constituiria uma tentativa de se reduzir os impulsos naturalizados e de acolher os estímulos de uma maneira mais espontânea, não viciada por hábitos cotidianos, ou por tudo aquilo que pudesse evocar a presença do ator em prejuízo da personagem. No caso da ideia de neutralidade, pode-se dizer que o que se pretende é normatizar o gestual do ator para que este não hiper-atue ou não permitir que certos traços de sua personalidade se sobreponham ao desempenho da ação do personagem. A neutralidade pode ser compreendida aqui como um filtro que procura separar a subjetividade do ator da objetividade de sua arte. 


\section{O olhar fenomenológico}

Entende-se que a fenomenologia esteja interessada em compreender os fenômenos em sua essência, livre de juízo de valor. Contudo, isso não significa negar sua existência, e por isso a fenomenologia "é também uma filosofia que repõe as essências na existência, e não pensa que se possa compreender o homem e o mundo de outra maneira senão a partir de sua 'facticidade", considerando as limitações perceptivas do sujeito para o qual "o mundo já está sempre 'ali', antes da reflexão" (Merleau-Ponty, 1999, p. 01). Nesse sentido, é possivel de se compreender que as preocupações da fenomenologia estão muito além de descobrir as etapas do processo pelo qual se dá a tomada de consciência do fenômeno. O método fenomenológico, também propõe-se a desenvolver mecanismos capazes de produzir por indução a epoché: a suspensão do julgamento, ou a abstração da atitude natural. As tendências são muito diversas e a fenomenologia se difundiu por inúmeros segmentos, mas o que se pode destacar neste artigo é que por meio do método fenomenológico seria desejável provocar a mudança de atenção sobre o fato ou fenômeno experienciado permitindo, até quem sabe, controlar a reversão da recepção, para se conseguir analisar e diferenciar aquilo que provém de uma interpretação do sujeito daquilo que realmente é constituinte como essencial ao fenômeno. Essa manobra, composta de um ciclo de procedimentos autossuficientes, seria chamada de ato redutivo, ou redução fenomenológica. Partindo desse pressuposto, podemos concluir que a fenomenologia estaria interessada em detectar a "presença inalienável" do sujeito para restabelecer o "contato ingênuo com o mundo" (Merleau-Ponty, 1999, p. 01). Consequentemente, é exatamente neste sentido que podemos perceber uma forte aproximação do conceito de redução fenomenológica com a ideia da máscara neutra (ou nobre): ambos funcionariam como métodos para se detectar a subjetividade e conservar a objetividade, ou melhor dizendo, a essência, ou a neutralidade.

A neutralidade parece ser um conceito difícil de ser assimilado na prática. Tendo em vista necessidade de se estabelecer uma comparação consistente entre 
o método fenomenológico e a máscara neutra, recorreremos agora a um outro exemplo para tentar elucidar melhor o pensamento por trás do argumento.

Em seu livro, O que vemos, o que nos olha, Georges Didi-Huberman (1998) desenvolveu uma discussão bastante pertinente a respeito da neutralidade no capítulo intitulado $A$ inelutável cisão do ver. Neste capítulo em especial, DidiHuberman procurou encontrar a reverberação de certas questões fenomenológicas na obra Ulisses, de James Joyce. Em sua narrativa, DidiHuberman, sustenta que a percepção estaria ligada inseparavelmente com o tangível e recorre ao conceito de diáfano (que permite a passagem da luz, transparente, límpido), já presente em Aristóteles, para tentar explicar o choque da visão "com o inelutável volume dos corpos" (Didi-Huberman, 1998, p. 30) e comparar essa travessia do sentido com a ideia de atravessar um obstáculo, talvez perfurado, feito de vazios.

Didi-Huberman destacou a maneira como o personagem Stephen Dedalus foi afetado pela morte da mãe: "uma coerção ontológica, medusante, em que tudo o que se apresenta a ver é olhado pela perda de sua mãe". Nesse sentido, podemos supor que o autor propõe a ideia de que um olhar neutro sobre as coisas vistas se torna algo afetado conforme lidamos com as perdas e experiências da vida. A perda se faz compreender aqui a partir de um vazio ou algo impossível de se reviver. O autor cita o exemplo da contemplação do mar que Dedalus faz no qual o mar estaria "carregado de todas as gravidezes e de todas as mortes por vir" enquanto nós nos limitamos a compreender o "poder inquietante de seu fundo" a partir do olhar da sua superfície. Dentro desta perspectiva somos convidados a supor que esta contemplação seria "um trabalho do sintoma no qual o que vemos é suportado por (e remetido a) uma obra de perda". Ou como Joyce teria dito: "fechamos os olhos para ver." (Didi-Huberman, 1998, p. 30-34).

Concernente ao trabalho do ator com a máscara neutra, pode-se dizer que a expressão de Joyce "fechar os olhos para ver" seria uma metáfora bastante útil para pensarmos o trabalho de treinamento do ator, no sentido de que se faz necessário abrir mão em cena daquilo que é parte constituinte da sua experiência particular (podemos denominar de corpo cotidiano ou vulgar) para se criar uma 
nova forma de ser visto (corpo poético). Seria a partir da criação de um "estado diáfano", vazio e transparente, que o ator, lutando contra o inelutável volume de seu corpo cotidiano ou vulgar, repleto de trejeitos e hábitos, permitiria que o olhar do espectador the atravessasse para ver não mais o seu corpo de ator, mas um corpo poético. Nesse caso, trata-se de uma experiência de perda, que funcionaria no mesmo sentido da redução fenomenológica, no qual é preciso criar um método para se aproximar da essência, ou da neutralidade, ainda que ela seja inatingível por completo. A máscara neutra poderia funcionar como este método.

Despertar a máscara neutra é diferente de simplesmente vesti-la. Quando o ator experimenta a máscara neutra, de alguma forma ele se desnuda. A ausência da face revela o corpo do ator, deixando a neutralidade da máscara ser preenchida por suas idiossincrasias. Quando o ator desperta a máscara essa passa a determinar sua ação, sua atitude corporal, suas reações. Nesse caso, é o ator que está servindo à máscara.

Além da especificidade da máscara neutra, podemos considerar que existe uma questão mais ampla sobre a psicologia por trás do uso das máscaras. É possível de se entender uma máscara, de uma maneira geral, como uma espécie de dispositivo ativador de corporeidades, capaz de propor a modificação de circuitos sensíveis para alterar e condicionar o comportamento à uma lógica imposta. É perceptível esse modo de agir diferenciado, como algo ativado no corpo do ator voluntariamente. Trata-se de uma tentativa, por parte do ator afectado pela máscara, de criar um método de atuação capaz de eximir as pessoalidades, controlar os impulsos indesejáveis e cercear tudo aquilo que não é apropriado para a movimentação, atuando numa relação de consubstanciação com aquilo que deixou de ser apenas um objeto e mesclou-se a sua imagem. O simples objeto, outrora morto, ganha vida através da sensibilidade do ator, que deverá instalar uma nova consciência com o intuito de provocar no próprio corpo uma atuação diferenciada. O artefato acoplado ao corpo poderá explorar reações distintas daquelas já acolhidas pelo ator. Este terceiro ser, poderia se cogitar dizer, talvez se torne o resultado de uma relação simbiótica entre o ator e a máscara. 


\section{Referências}

AMARAL, Ana Maria. O ator e seus duplos: máscaras, bonecos e objetos. São Paulo: SENAC, 2002.

DIDI-HUBERMAN, G. O que vemos, o que nos olha. Trad. Paulo Neves. São Paulo: Editora S4, 1998.

DULLIN, Charles. «Improvisation» [Improvisação], p. 109-131, in: Souvenirs et notes de travail d'un acteur [Lembranças e Notas de Trabalho de um Ator]. Paris: Odette Lieutier, 1946. In: DULLIN, Charles. Improvisação. Trad. José Ronaldo Faleiro. Urdimento, Florianópolis, n. 18, p. 171-180, mar. 2018.

FREIXE, Guy. Les Utopies du masque sur les scènes Européennes du XXe siècle [As Utopias da Máscara nos Palcos Europeus do século XX]. Montpellier: l'Entretemps, 2010. [Tradução inédita de José Ronaldo Faleiro.]

LECOQ, Jaques. Le corps poétique [O corpo poético]. Paris: Actes Sud, 1997.

LEVEQUE, Jean-Jacques. Les Annees Folles. Le trionphe de l'Art moderne (19181939). Courbevoie: Art Creation Realisation éd., 1992.

MERLEAU-PONTY, Maurice. Fenomenologia da Percepção. SP: Martins Fontes, 1999. RIMBAUD, Arthur. Poésies. Paris: Librairie Générale Française, 1984.

ROMANO, Lúcia. O teatro do corpo manifesto. São Paulo: Perspectiva, 2013.

Recebido em: 08/06/2020

Aprovado em: 30/10/2020 